
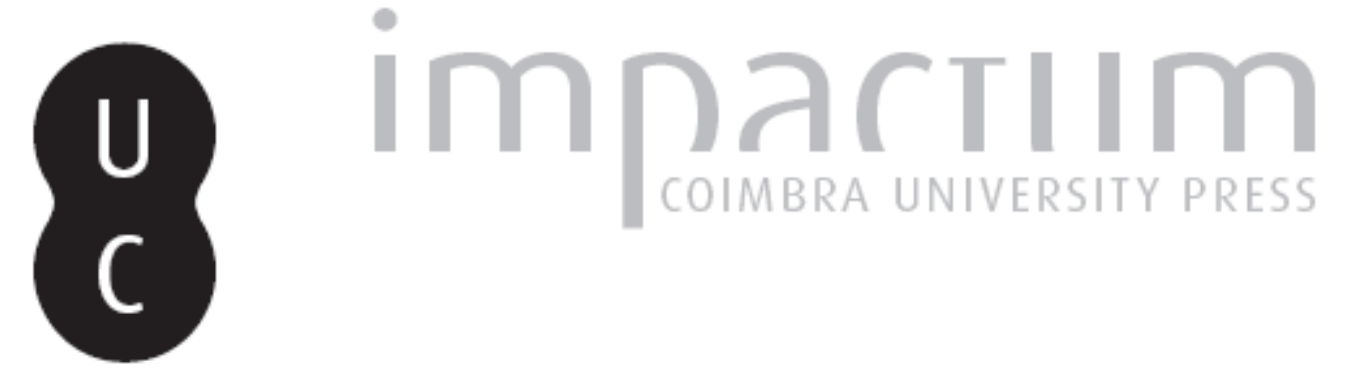

\title{
António Sérgio e Coimbra
}

Autor(es): $\quad$ Franco, Matilde Pessoa de Figueiredo Sousa

Publicado por: Imprensa da Universidade de Coimbra

URL persistente:

URI:http://hdl.handle.net/10316.2/43841

DOI:

DOI:https://doi.org/10.14195/2183-8925_6_13

Accessed : $\quad$ 26-Apr-2023 13:57:46

A navegação consulta e descarregamento dos títulos inseridos nas Bibliotecas Digitais UC Digitalis, UC Pombalina e UC Impactum, pressupõem a aceitação plena e sem reservas dos Termos e Condições de Uso destas Bibliotecas Digitais, disponíveis em https://digitalis.uc.pt/pt-pt/termos.

Conforme exposto nos referidos Termos e Condições de Uso, o descarregamento de títulos de acesso restrito requer uma licença válida de autorização devendo o utilizador aceder ao(s) documento(s) a partir de um endereço de IP da instituição detentora da supramencionada licença.

Ao utilizador é apenas permitido o descarregamento para uso pessoal, pelo que o emprego do(s) título(s) descarregado(s) para outro fim, designadamente comercial, carece de autorização do respetivo autor ou editor da obra.

Na medida em que todas as obras da UC Digitalis se encontram protegidas pelo Código do Direito de Autor e Direitos Conexos e demais legislação aplicável, toda a cópia, parcial ou total, deste documento, nos casos em que é legalmente admitida, deverá conter ou fazer-se acompanhar por este aviso.

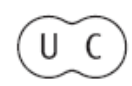




\section{REVISTA DE HISTORIA DAS IDEIAS 6}

\section{. \\ REVOLTAS E REVOLUCOEES}

*

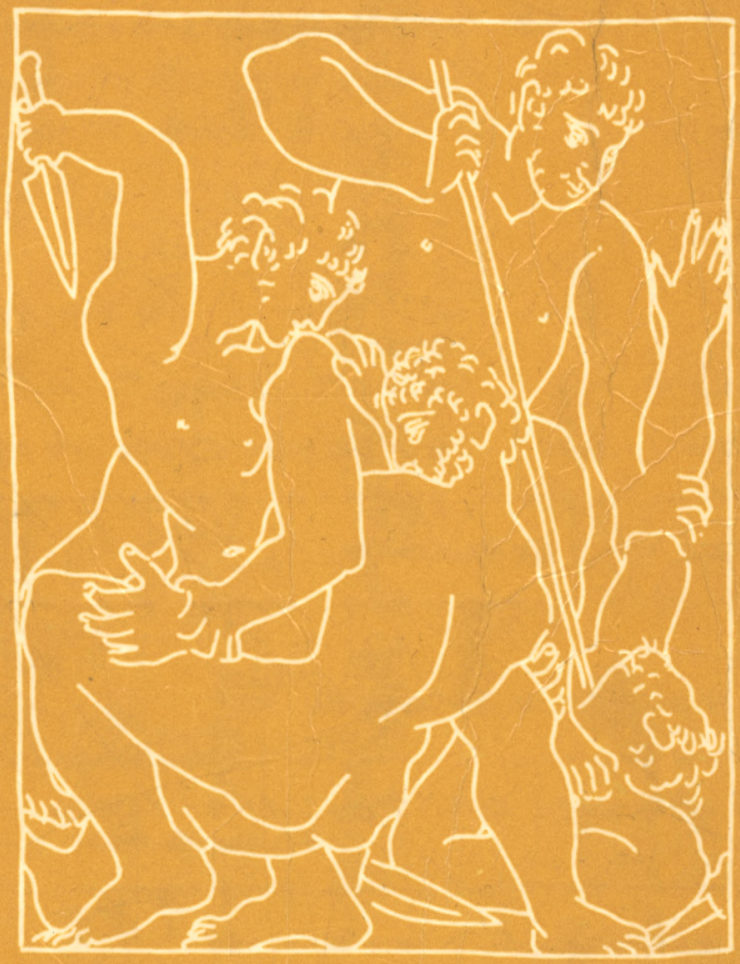

INSTITUTO DE HISTORIA E TEORIA DAS IDEIAS FACULDADE DE LETRAS 
MATILDE PESSOA DE FIGUEIREDO SOUSA FRANCO*

\section{ANTÓNIO SÉRGIO E COIMBRA}

A propósito da homenagem que a Universidade de Coimbra acaba de prestar a António Sérgio, sobretudo através de uma exposição e da publicação de dois volumes que lhe são consagrados pela Revista de História das Ideias, do Instituto de História e Teoria das Ideias, da Faculdade de Letras, venho referir três cartas que, de Coimbra, há cerca de sessenta anos, foram endereçadas a António Sérgio e que julgo serem inéditas, pelo menos na totalidade.

Coimbra de ontem e Coimbra de hoje homenageia António Sérgio.

1. COIMBRA NA VIDA DE SERGIO

As cartas a que me refiro foram escritas a propósito da polémica sobre o "Seiscentismo" e todas em papel timbrado da Universidade de Coimbra, em 16 e 22 de Junho e 8 de Julho de 1926, respectivamente por Manuel da Silva Gaio, Manuel Gonçalves Cerejeira e Luís Carrisso, numa amostra da correspondência trocada entre Sérgio e intelectuais coimbricenses.

António Sérgio residia já então na sua casa da Travessa do Moinho de Vento, n. ${ }^{\circ} 4$, à Estrela, mas pouco depois viria a sofrer a "primeira emigração", a qual durou de 1926 a 1933.

Repare-se que em 1926 António Sérgio proferiu em Coimbra a conferência O Reino Cadaveroso ou o Problema da Cultura em Portugal (cujo texto vem no II volume dos Ensaios, de 1929) e no volume III dos Ensaios publicou, em 1932, Considerações sobre o Problema da Cultura (com dedicatória:

* Directora do Palácio Nacional de Sintra. 
«A Joaquim de Carvalho, Vieira de Campos, Sílvio de Lima e à Associação dos Estudantes da Faculdade de Letras da Universidade de Coimbra»). Nas anotações finais a este texto, Sérgio esclareceu as condições em que ele surgiu, a convite da Associação dos Estudantes da Faculdade de Letras da Universidade de Coimbra, estando Sérgio exilado em Paris, para ser lido por Joaquim de Carvalho, como conferência inaugural da «Semana da Cultura».

O Professor Joaquim de Carvalho (1892-1958), filósofo e professor de História da Filosofia na Faculdade de Letras da Universidade de Coimbra e que foi, de 1921 a 1935, administrador da Imprensa da Universidade de Coimbra, promoveu a edição de várias obras, traduzidas, prefaciadas e comentadas por Sárgio.

Outras obras de Sérgio, ou por ele traduzidas, vêem a luz também em Coimbra, como: a 2.. ${ }^{a}$ edição do $10^{\circ}$ volume dos Ensaios (em 1949, na "Atlântida»); também na "Atlântida", mas para a "Biblioteca Filosófica» - dirigida e fundada por Joaquim de Carvalho - Três Diálogos entre Hilas e Filonous em oposição aos cépticos e ateus, de George Berkeley; Os Problemas da Filosofia, de Bertrand Russell (1939), publicada esta por Arménio Amado, "um nosso culto editor», como se lhe refere nos Ensaios, etc.

Para apontar alguns elos de Sérgio com Coimbra, refira-se ainda a questão com o Professor Luís Cabral de Moncada (nascido em 1888 e recentemente falecido), professor da Faculdade de Direito, vice-reitor da Universidade de Coimbra de 1932 a 1940 . A questão (que durou dois anos) surgiu a propósito da conferência que o Professor Cabral de Moncada, na altura muito próximo do pensamento integralista, proferiu, na Associação Académica de Coimbra, em 1 de Dezembro de 1927 , sobre "Restauração do pensamento político português».

\section{A POLÉMICA DO «SEISCENTISMO»}

Para os Caros Leitores que não se recordem da atrás referida polémica gerada à volta do "Seiscentismo», permita-se-me anotar que, na sequência da polémica sobre D. Sebastião, em 1924 Sérgio comentou, na revista Lusitânia, onde era o crítico oficial, o livro O Seiscentismo em Portugal, da autoria de Manuel Múrias, então saído a lume, e no qual «se fazia uma paradoxal apologia da cultura portuguesa do século XVII", segundo as palavras do próprio Sérgio. Depois disso, houve insistências para que a revista Lusitânia publicasse um texto de António Sardinha (também monárquico e 
defensor do integralismo lusitano, como Múrias), em que se elogiava o trabalho de Múrias e contraditava as ideias de Sérgio. Este queria, pelo menos, publicar, no mesmo número da revista, a defesa da sua posição, mas pediram.lhe que ela só saísse no número seguinte. Pouco após faleceu António Sardinha (em Janeiro de 1925) e as ideias do artigo dele iam exercendo influência "perniciosíssima", na expressão sergiana. Por isso, António Sérgio resolveu publicar na Seara Nova (n. ${ }^{\circ} 56$ e 57, em Outubro de 1925), o artigo em que lhe respondia, explicando essa sua atitude numa nota prévia: «.... Insisto na minha tese, porque creio por essa fórma prestar um serviço à Comunidade, - intenção que António Sardinha, se aqui estivesse, seria o primeiro, a reconhecer....» Já em 1926, a. Seara Nova reproduz este artigo de Sérgio, mas em folheto, com a transcrição mais completa de uns textos, um prefácio de nove páginas do autor e, em apêndice, uma carta que este, na Seara Nova, escreveu aos jovens "seareiros» de Coimbra a propósito das hostilidades que sofreu por causa do artigo. Significativamente o folheto intitula-se $O$ Seiscentismo. Reprodução do artigo em que, segundo dizem os que me odeiam, insultei um morto e falsifiquei textos.

A polémica sobre o "Seiscentismo», designadamente ao mencionado folheto então publicado, se referem as três cartas endereçadas a Sérgio e que seguidamente se transcrevem, na íntegra, e por ordem da data em que foram escritas. Terá interesse anotar que o destinatário destas missivas tinha então 42 anos, o futuro Cardeal Cerejeira contava 37, o Professor Carrisso 60 e Silva Gaio 66 anos.

\section{CARTA DE MANUEL DA SILVA GAIO}

Manuel da Silva Gaio, poeta e publicista, nasceu e faleceu em Coimbra (1860-1934); era filho de António da Silva Gaio, médico e professor da Universidade de Coimbra, o autor do célebre romance histórico Mário-Episódios das Lutas Civis Portuguesas de 1820-1834. Manuel da Silva Gaio dedicou-se ao jornalismo, à crónica e à poesia; a publicação, em 1887, de Primeiras Rimas, marca uma primeira fase na sua vida literária.

A troca de correspondência de Manuel da Silva Gaio com António Sérgio iniciou-se, pelo menos, quinze anos antes da carta que se agora publica.

A carta é escrita em papel timbrado: "Universidade de Coimbra. Secretaria Geral. Gabinete do Secretário». 
Meu caro António Sérgio

Venho responder, sóbria e concretamente, ás perguntas com que o meu Amigo fecha, na nova edição em folheto, o seu admiravel artigo sobre o Seiscentismo - outra obra do bom combate pela reforma da Mentalidade portuguesa:

a) - Não encontrei insultos a António Sardinha - antes, pelo contrário, notei no decurso de todo o artigo, embora de viva energia dialectica, um constante tom fraternal e amavel.

Digo o que sinto, e como amigo de António Sardinha, a quem muito quiz. Porque não aceito a ideia de que criticar e rebater as opiniões de alguem - vivo ou morto - represente uma ofensa á pessôa criticada ou á memoria da pessôa criticada; e, fóra do legítimo campo da controvérsia histórica, onde o meu caro António Sérgio o combateu, nada ha, no artigo, susceptível de ser apontado como injurioso ou menos justo para a saudosa personalidade de António Sardinha - do homem e do escritor.

- Tal ideia só podia germinar e vingar num país onde se entende que a função da crítica é louvar... quando não seja... agredir. -

b) - Não vejo que as partes do livro de Gonzague Truc (para mim desconhecido) pelo meu Amigo transcritas agora destruam a conclusão tirada das partes transcritas da primeira vez;

c) - Nada autoriza, em face dos textos transcritos, que a propósito dêles se fale de falsificações.

Acrescentaria que nunca eu poderia admitir a suposição de que António Sérgio falsificasse um texto.

Coimbra -

Manuel da Silva Gaio»

\section{CARTA DE MANUEL GONÇALVES CEREJEIRA}

O futuro Cardeal Cerejeira era, desde 1919, professor catedrático da Faculdade de Letras da Universidade de Coimbra, do $4 .^{\circ}$ Grupo, Ciências Históricas. Regeu aí as cadeiras de História Antiga, Propedêutica e História Geral da Civilização, História Moderna e Contemporânea, História de Portugal e História das Religiões, até 1928, quando teve de deixar Coimbra, por o Papa Pio XI o ter escolhido para Arcebispo titular de Mitilene, auxiliar do Cardeal Patriarca de Lisboa. Pio XI nomeou-o Patriarca de Lisboa em 1929, criandono Cardeal, ainda nesse ano.

A referida carta é escrita em papel timbrado: "Universidade de Coimbra. Faculdade de Letras. Instituto de Estudos Históricos» e, a propósito da questão sobre o "Seiscentismo", tem sido várias vezes referida a posição do Cardeal Cerejeira então aqui expressa. 


\section{António Sérgio e Coimbra}

«22.VI.26

\section{Ex. ${ }^{m o}$ Senhor António Sergio}

Agradeço a V. Ex.cia o oferecimento do seu artigo agora publicado em folheto. Sabe V. Ex.cia que o não acompanho em todos os seus juízos (o que sinceramente lamento); mas isso não me impede de lhe fazer a justiça que como homem e como cristão lhe devo.

Sôbre o artigo em questão, lendo-o e relendo-o atentamente, e comparando-o até com o que dele se escreveu, sinto grande gôsto em reconhecer que, a meu juízo,

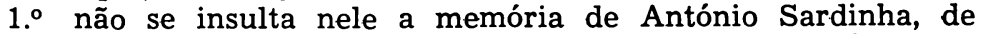
quem fui amigo e sou sempre admirador (o que não quer dizer que o acompanhe sempre no que escreveu), de textos.

2. nem há coisa lá que se possa chamar verdadeira falsificação

Disse, sinto o gôsto, porque embora não tenha a honra de conhecer pessoalmente V. Ex.cia, basta-me saber que é meu semelhante - e sei muito mais a favor de V. Ex.cia - para sentir prazer em verificar a sem-razão de acusações insubsistentes.

Discutir as ideias de alguem que morreu, não constitui, parece-me a mim, ofensa para êle, mormente quando isso se faz em termos de gente civilizada; e até pode constituir uma homenagem, pois se não discute o que discussão não merece. As opiniōes, desde que foram publicadas, tornam-se, por assim dizer, de domínio público, e quemquer pode sentir-se no dever de as combater... com argumentos, claro está.

Não creio que se possa chamar falsificações à simples omissão de frases desnecessárias, aliás prudentemente indicada - a menos que as frases omitidas alterassem essencialmente o significado das transcritas. Ora isto não o consegui eu descobrir. E aquilo é processo corrente entre pessoas que escrevem, não falo já das que escrevinham.

Poderia fechar aqui esta carta. Deixe-me somente acrescentar que V. Ex.cia não tem nada que agradecer-me por ela. Para mim, servir a verdade é o mesmo que servir a Deus. Até nem compreendo bem como V. Ex.cia, não servindo a Deus, se possa sentir obrigado a servir a verdade, ou aquilo que V. Ex.cia julga como tal...

Com o testemunho da minha leal camaradagem intelectual, subscrevo-me

De V. Ex.cia

m.to at.o v.or e ad.or

M. Gonçalves Cerejeira

P.S. V. Ex.cia pode fazer desta carta o uso $\bar{q}$ entender G. C.»

5. CARTA DE LUIS WITTNICH CARRISSO

Luís Wittnich Carrisso, professor e naturalista, era, desde 1918, professor catedrático da Faculdade de Ciências de Coimbra, assumindo, também, a direcção do Instituto Botânico. Foi presidente da Sociedade Broteriana e desempenhou vários outros cargos, entre os quais o de vice-reitor em exercício da 
Universidade de Coimbra (1929-1931) e o de presidente da Câmara Municipal de Coimbra (1935).

A carta em questão é escrita em papel timbrado: «Universidade de Coimbra. Instituto Botânico Dr. Julio Henriques».

«8 de Julho de 1926

Ex. ${ }^{\text {mo }}$ Snr. Antonio Sergio,

e meu Ex. ${ }^{\text {mo }}$ Amigo.

Venho agradecer-lhe a amavel oferta do seu «Seiscentismo». O magnífico «prefacio» que era para mim materia nova (conhecia já o artigo da Seara Nova) onde V. Ex. ${ }^{a}$ tão brilhantemente define o seu ponto de vista, li-o de um trago, e aqui lhe venho apresentar a minha modesta adesão, e o meu sincero aplauso.

Em Portugal estamos muito mais baixo do que muita gente supõe. Ha a realizar uma grande obra de educação: e onde a necessidade da sua obra se faz mais sentir, é precisamente naqueles que sabem ler e escrever. Sinto isso a cada passo, na minha vida de professor: e considero o problema da educação como bem mais grave do que o da instrução propriamente dita.

Subscrevo-me, desejando-lhe a coragem e a energia necessárias para continuar combatendo. Simples soldado na lide, de longe o acompanharei, com o mais vivo e sincero interesse.

\author{
Creia na sincera estima e consideração do \\ seu amigo m.to atento \\ Luis W. Carrisso»
}

\title{
6. A GUISA DE CONCLUSÃO
}

No mencionado apêndice incluído no folheto sobre $O$ Seiscentismo, o qual se intitulou Aos jovens "seareiros» de Coimbra, sobre a maneira de lidar com os inimigos da Luz $e$ da Razão, António Sérgio escreve que: «.... a autêntica prègação da democracia é dar o exemplo do "self-control»; é procurar a virtude em todos os actos; é ter sempre por objecto o bem da Grei», e por exemplo, também: "O que eu vos peço, porém, não é sómente que sejais estóicos; não é sómente o aperfeiçoamento próprio: mas que metais o dorso a uma maior emprêsa - muito maior, - que é a regeneração de Portugal». Este será um bom apelo sergiano aos jovens e aos homens de boa vontade de todas as épocas. 